\title{
Screening for trauma in children and adolescents: The validity of the trumatic stress disorder scale of the screen for child anxiety related emotional disorders
}

Citation for published version (APA):

Muris, P. E. H. M., Merckelbach, H. L. G. J., \& Meesters, C. M. G. (2000). Screening for trauma in children and adolescents: The validity of the trumatic stress disorder scale of the screen for child anxiety related emotional disorders. Journal of Clinical Child Psychology, 29(3), 406-413.

https://doi.org/10.1207/S15374424JCCP2903_11

Document status and date:

Published: 01/01/2000

DOI:

10.1207/S15374424JCCP2903 11

Document Version:

Publisher's PDF, also known as Version of record

Please check the document version of this publication:

- A submitted manuscript is the version of the article upon submission and before peer-review. There can be important differences between the submitted version and the official published version of record.

People interested in the research are advised to contact the author for the final version of the publication, or visit the DOI to the publisher's website.

- The final author version and the galley proof are versions of the publication after peer review.

- The final published version features the final layout of the paper including the volume, issue and page numbers.

Link to publication

\footnotetext{
General rights rights.

- You may freely distribute the URL identifying the publication in the public portal. please follow below link for the End User Agreement:

www.umlib.nl/taverne-license

Take down policy

If you believe that this document breaches copyright please contact us at:

repository@maastrichtuniversity.nl

providing details and we will investigate your claim.
}

Copyright and moral rights for the publications made accessible in the public portal are retained by the authors and/or other copyright owners and it is a condition of accessing publications that users recognise and abide by the legal requirements associated with these

- Users may download and print one copy of any publication from the public portal for the purpose of private study or research.

- You may not further distribute the material or use it for any profit-making activity or commercial gain

If the publication is distributed under the terms of Article $25 \mathrm{fa}$ of the Dutch Copyright Act, indicated by the "Taverne" license above, 


\title{
Screening for Trauma in Children and Adolescents: The Validity of the Traumatic Stress Disorder Scale of the Screen for Child Anxiety Related Emotional Disorders
}

\author{
Peter Muris \\ Department of Medical, Clinical, and Experimental Psychology, Maastricht University, The Netherlands \\ Harald Merckelbach \\ Department of Psychology, Maastricht University, The Netherlands

\section{Petra Körver and Cor Meesters} \\ Department of Medical, Clinical, and Experimental Psychology, Maastricht University. The Netherlands
}

\begin{abstract}
Examined the validity of the Traumatic Stress Disorder scale of the Screen for Child Anxiety Related Emotional Disorders (SCARED), a recently developed self-report questionnaire measuring Diagnostic and Statistical Manual of Mental Disorders (4th ed. [DSM-IV]; American Psychiatric Association, 1994) defined anxiety disorders symptoms in children. A large sample of normal schoolchildren $(N=996)$ ages 7 to 19 years completed the SCARED. Children who scored high on the SCARED Traumatic Stress Disorder scale (i.e., trauma group; $n=43$ ) and children who scored low on this scale (i.e., control group; $n=43$ ) were then interviewed about their most aversive life event. In addition, children completed self-report questionnaires of traumatic experiences and pasttraumatic stress disorder (PTSD) symptomatology. Results showed that children in the trauma group more frequently reported life events that independent judges considered to be 'potentially traumatic' than did control children. Furthermore, children in the trauma group reported having experienced more traumatic incidents and had higher scores on PTSD-related questionnaires compared with control children. Moreover, trauma group children more frequently fulfilled DSM-IV criteria for PTSD than did control children. The results of this study support the validity of the Traumatic Stress Disorder scale of the SCARED.
\end{abstract}

According to the Diagnostic and Statistical Manual of Mental Disorders (4th ed. [DSM-IV]; American Psychiatric Association, 1994), the essential feature of posttraumatic stress disorder (PTSD) is

the development of characteristic symptoms following exposure to an extreme traumatic stressor involving direct personal experience of an event that involves actual or threatened death or serious injury, or other threat to one's physical integrity; or witnessing an event that involves death, injury, or a threat to the physical integrity of another person; or learning about unexpected or violent death, serious harm, or threat of death or injury experienced by a family member or other close associate. (p. 424)

We thank the teachers, staff, and children of primary schools Talmaschool, De Tovercircel, and De Slagboom and secondary school Eijkhagencollege in Heerlen, The Netherlands for their participation in this study.

Requests for reprints should be sent to Peter Muris, Department of Medical, Clinical, and Experimental Psychology, Mastricht University, P.O. Box 616,6200 MD, Maastricht, The Netherlands. E-mail: p.murisigdep.unimaas, n]
The key features of PTSD involve reexperiencing the traumatic event, avoidance of stimuli associated with the trauma or numbing of general responsiveness, and increased arousal (for a detailed analysis, see Foa, Riggs, \& Gershuny, 1995).

Over the past few years, there has been an increased interest in the psychological consequences of traumatic experiences in children. Although the precise prevalence rates of PTSD in children and adolescents remain unknown, a number of studies have indicated that children are at an increased risk for developing PTSD if they have been exposed to lifethreatening events such as criminal assaults (Pynoos \& Nader, 1988), kidnapping (Terr, 1979), combat (Clarke, Sack, \& Goff, 1993), severe illness (Nader, Stuber, \& Pynoos, 1991), catastrophes (Yule \& Williams, 1990), physical and sexual abuse (Famularo, Kinscherff, \& Fenton, 1990; Wolfe, Gentile, \& Wolfe, 1989), and natural disasters (Lonigan, Shannon, Finch, Daugherty, \& Saylor, 1991). Furthermore, it is well documented that traumatized children frequently exhibit symptoms of disorders other than PTSD, including anxiety disorders such as separation 
anxiety disorder and generalized anxiety disorder (see Curry \& Bennett Murphy, 1995).

Epidemiological surveys on the prevalence of traumatic experiences in children as well as diagnostic screening of clinically referred children critically depend on reliable and valid instruments with which it is possible to identify children who have experienced traumatic events. Two recently developed instruments that can be helpful in this respect are the Childhood Trauma Questionnaire (CTQ; Bernstein, Ahluvalia, Pogge, \& Handelsman, 1997) and the Self-Reported Post-Traumatic Symptomatology (SRPTS; March, Amaya-Jackson, Terry, \& Costanzo, 1997). Both questionnaires ask children to indicate whether they ever have experienced frightening events such as violence, war, natural disasters, and sexual abuse.

The Screen for Child Anxiety Related Emotional Disorders (SCARED), which was developed by Birmaher et al. (1997), is a self-report questionnaire that has a much broader focus. Unlike traditional childhood anxiety measures such as the Fear Survey Schedule for Children (Ollendick, 1983) and the Revised Children's Manifest Anxiety Scale (Reynolds \& Richmond, 1978), the SCARED intends to measure symptoms of the anxiety disorders that, according to the $D S M-I V$, may occur in children: separation anxiety disorder, generalized anxiety disorder, social phobia, panic disorder, obsessive-compulsive disorder, specific phobia, and, most pertinent to this article, PTSD (see Muris, Merckelbach, Schmidt, \& Mayer, 1999).

The SCARED Traumatic Stress Disorder scale consists of four items: (a) "I have frightening dreams about a very aversive event I once experienced," (b) "I try not to think about a very aversive event I once experienced," (c) "I get scared when I think back on a very aversive event I once experienced," and (d) "I have unbidden thoughts about a very aversive event I once experienced." The scale should be viewed as a brief, initial screen for the presence of PTSD symptoms before confronting children with more extensive and specific but also more taxing questionnaires such as the aforementioned CTQ and SRPTS.

So far, no study has examined the validity of the SCARED Traumatic Stress Disorder scale. Accordingly, little is known about the type of experiences to which children refer when they respond positively to the pertinent items. This study sought to investigate this issue. A large sample of normal schoolchildren ages 7 to 19 years completed the SCARED. Children who scored high on the SCARED Traumatic Stress Disorder scale (i.e., 'trauma group') and control children (matched on school, sex, and age) were then interviewed about their most aversive life event. In addition, children completed self-report questionnaires of traumatic experiences and PTSD symptomatology. We anticipated that children in the trauma group would report more aversive life events, a greater number of traumatic experiences, and more severe PTSD symptomatology than children in the control group.

An additional purpose of this study was to investigate the connection between traumatic life events and anxiety disorders symptoms. Previous studies have shown that negative life events such as parental separation and divorce, death of significant family members, and family conflict have a heightened frequency among clinically anxious children (Benjamin, Costello, \& Warren, 1990; Goodyer, Wright, \& Altham, 1990; Kashani et al., 1990). Assuming that the children in the trauma group, indeed, report a larger number of aversive life events, we hypothesized that this group would also display higher levels of anxiety disorder symptomatology than children in the control group.

\section{Method}

\section{Children}

The parents of 1,228 children of three primary schools and one secondary school were sent a letter in which they were informed about the first phase of our research project: anxiety symptoms in children. Eighty-one percent of the parents gave permission for their children to participate in the research project. The sample consisted of 996 children ( 513 boys and 483 girls) with a mean age of 12.8 years $(S D=2.5$, range $=$ $7-19$ years). These children completed the SCARED in their classrooms in the presence of the teacher and a research assistant. Children were instructed to read each item and to rate the frequency of that symptom. In younger children (ages 7 to 9), SCARED items were read aloud. Children were explicitly told that they could ask the teacher or the research assistant for help if they had any questions about the items.

About 2 months after administration of the SCARED, the parents of the 55 children $(5.5 \%$ of the total sample) who scored high on the Traumatic Stress Disorder scale of the SCARED (i.e., children who responded with often or always to all four items; see subsequent discussion) were contacted again, this time obtaining written consent for the second phase of the study. Parents were informed that their children would be interviewed about the origins of anxiety symptoms. The parents of 43 children ( $78 \% ; 18$ boys and 25 girls) consented. Mean age of these children was 11.8 years $(S D=2.6$, range $=7-19$ years $)$. This group will hereafter be referred to as the trauma group. Forty-three control children were recruited from the children who scored low on the Traumatic Stress Disorder scale of the SCARED (i.e., children who responded with never to all four items). Trauma group children and control children were matched on school type, sex, and age. 


\section{Measures}

The 66-item SCARED (see Muris, Merckelbach, Schmidt, \& Mayer, 1999) is a self-report questionnaire measuring $D S M-I V$-defined anxiety disorder symptomatology. The SCARED consists of nine subscales: Panic Disorder (13 items; e.g., "I am afraid of having panic attacks"); Separation Anxiety Disorder (12 items; e.g. "I don't like being away from my family"); Generalized Anxiety Disorder (9 items; e.g., "I worry about things working out for me"); Social Phobia (4 items; e.g., "I don't like to be with unfamiliar people"); Specific Phobias (Animal Phobia: 3 items; e.g., "I am afraid of an animal that is not really dangerous"; Situational-Environmental Phobia: 5 items; e.g. "I am afraid of the dark"; and Blood-Injection-Injury Phobia: 7 items; e.g., "I am afraid to go to the dentist"); Obsessive-Compulsive Disorder ( 9 items; e.g., "I have thoughts that frighten me"); and Traumatic Stress Disorder (4 items; mentioned in introduction). In this study, children were asked to rate the extent to which they experienced each anxiety symptom on a 4-point scale ranging from 1 (almost never), 2 (sometimes), 3 (often), to 4 (always). SCARED total score and subscale scores are derived by summing relevant items.

In the initial sample of 996 children, internal consistency of the SCARED Traumatic Stress Disorder scale was .80 . Furthermore, this scale correlated between .24 (Animal Phobia) and .58 (Panic Disorder) with the other SCARED subscales.

Previous research has shown that the 66-item SCARED possesses adequate internal consistency (with alphas generally greater than 60 for all subscales; Muris, Merckelbach, Schmidt, \& Mayer, 1999), sufficient test-retest reliability (with test-retest correlation of .81 for the SCARED total score; Muris, Merckelbach, Van Brakel, \& Mayer, 1999), and acceptable validity, that is, the SCARED correlates substantially with traditional childhood anxiety measures (Muris et al., 1998) and discriminates between children with and without anxiety disorders (Muris, Merckelbach, Mayer, \& Prins, 2000). The factor structure in normal children is unidimensional (i.e., one factor; see Muris, Merckelbach, Schmidt, \& Mayer, 1999), but there is evidence that anxiety scales emerge as separate factors when data of clinically referred children are analyzed (Birmaher et al., 1997).

The Traumatic Incidents Scale (TIS) was designed for the purpose of this study and contained 31 items, all referring to traumatic incidents. The items were derived from the CTQ (Bernstein et al., 1997) and SRPTS (March et al., 1997) and pertain to various types of traumatic events: sexual abuse (e.g., "Someone touched me in a sexual way"); physical abuse (e.g., "I have been beaten up badly"); accidents (e.g., "I was involved in a bad car or bike accident"); illness or death (e.g., "I got so sick I almost died"); life events (e.g., "My parents are divorced or do not live together"); and natural or man-made disasters (e.g., "I was witness of a robbery"). Using yes-no options, children indicated whether they had ever experienced such events.

The Impact of Event Scale (IES; Horowitz, Wilner, \& Alvarez, 1979) is a 15 -item scale that measures two crucial aspects of PTSD symptomatology, namely intrusive thinking (e.g., "Ithinkabout it when I don't mean to") and cognitive avoidance of traumatic intrusions (e.g. "I try to remove it from memory"). Each item has to be answered on a 4-point scale ranging from 1 (never), 2 (sometimes), 3 (often), to 4 (always). The IES is currently the most widely used instrument in research on PTSD in adults. Yule and colleagues (Yule \& Udwin, 1991; Yule \& Williams, 1990) used the scale with children age 8 to 16 years. These authors concluded that children who had survived a sea disaster found the IES questions meaningful and reported scores as high as those of traumatized adults. Dyregrov, Kuterovac, and Barath (1996) found the IES to possess good psychometric properties in children exposed to warfare.

The PTSD Reaction Index (PTSD-RI) was originally devised as an interview to assess PTSD symptoms in children (Pynoos et al., 1987). Shannon, Lonigan, Finch, and Taylor (1994) employed the PTSD-RI as a 14-item self-report measure that taps three clusters of PTSD symptoms: Reexperiencing (five items), Avoidance (four items), and Hyperarousal (five items). Each item has to be checked on a 4-point scale ranging from 1 (never), 2 (sometimes), 3 (often), to 4 (always). PTSD$\mathrm{RI}$ items are largely in keeping with the symptoms that are listed in the $D S M-I V$ to define the main criteria (i.e., Criteria B, C, and D) for PTSD.

\section{Interview and Procedure}

The interview was highly structured and lasted for maximally $30 \mathrm{~min}$. A trained research assistant who documented children's answers online carried it out individually in a separate room at school.

First, children were briefed about the purpose of the study. Children were explicitly told that the information they provided would remain strictly confidential. The interview started with questions about the child's most frightening experience: "What is the most frightening event you have ever experienced?" "What exactly happened?" "How did you react when this happened: What did you think or feel?" "When did this event happen?" "Are there certain things that you cannot do due to the fact that this event happened?" "Does the event influence your school work?" "Does the event influence your relationships with other children or adults?"

Children in the trauma group received additional questions about their responses to the items of the SCARED Traumatic Stress Disorder scale. More pre- 
cisely, they were asked to specify the aversive events they had referred to when completing these items:

Some time ago, you completed an anxiety questionnaire. Some of the questions had to do with a very aversive event you once experienced. You indicated on the questionnaire that you had frightening dreams about a very aversive event. About what event did you think when you rated this item?

You indicated on the questionnaire that you tried not to think about a very aversive event you once experienced. About what event did you think when you rated this item?

You indicated on the questionnaire that you became scared when you thought of a very aversive event you once experienced. About what event did you think when you rated this item?

You indicated on the questionnaire that you had unbidden thoughts about a very aversive event you once experienced. About what event did you think when you rated this item?

Finally, all children completed the IES and the PTSD-RI in relation to their most frightening experience and the TIS.

\section{Ratings of Aversive Experiences}

Vignettes (brief descriptions of the event) were made of the most aversive experiences described by the children of both groups during the interview. These vignettes were then given to three independent raters who were blind to children's group status. The raters, all psychologists with backgrounds in child psychopathology, were instructed to indicate which of the experiences they considered to be "potentially traumatic." On the basis of their evaluations, each experience was classified as either potentially traumatic or nontraumatic. Judges were quite unanimous in their evaluations: In $79.0 \%$ to $90.7 \%$ of the cases, their evaluations agreed (Cohen's kappa values varied between 0.60 and 0.80 ). Eventually, all discrepancies were resolved through discussion.

\section{Assessment of DSM-IV Criteria for PTSD}

$D S M-I V$ criteria for PTSD were assessed on the basis of children's responses during the interview and their questionnaire scores. More specifically, Criteria $B, C$, and D were based on children's scores on the PTSD-RI. To meet these criteria, children had to display a score of 3 (often) or 4 (always) on at least one item of PTSD-RI Re-experiencing scale (Criterion B), on at least three items of the PTSD-RI Avoidance scale (Criterion C), and on at least two items of the PTSD-RI Hyperarousal scale (Criterion D). Criteria A (traumatic event), $E$ (duration of 1 month), and $F$ (impairment) were assessed by two of the previously mentioned raters. Raters were provided with children's responses to the interview questions that pertained to their most frightening experience and asked to judge who of the children met these criteria. Percentages of agreement were $90.7 \%$ for Criterion A, $100 \%$ for Criterion E, and $100 \%$ for Criterion $\mathrm{F}$ (kappa values between 0.80 and 1.00). Furthermore, both raters identified the same 3 children as meeting the full criteria for PTSD.

\section{Results}

\section{Content of Children's Most Aversive Experience}

The large majority of children in the trauma group said that their responses to the Traumatic Stress Disorder items of the SCARED did, indeed, pertain to their most aversive experience as identified during the interview. For example, $81.4 \%$ of the children indicated that they had referred to their most aversive experience when responding with often or always to the SCARED item "I have frightening dreams about a very aversive event I once experienced." These percentages were even higher for the other SCARED Traumatic Stress Disorder items: $86.1 \%$ for "I try not to think about a very aversive event I once experienced," $95.4 \%$ for "I get scared when I think back of a very aversive event I once experienced," and $93.0 \%$ for "I have unbidden thoughts about a very aversive event I once experienced."

Table 1 provides brief descriptions of the most aversive experiences reported by children of both groups during the interview. As can be seen, the most frequent experiences in the trauma group were minor accident or incident $(n=7)$, death of a grandparent $(n=$ 5 ), divorce/severe problems at home $(n=5)$, death of a parent $(n=3)$, and rape $(n=3)$. In the control group, minor accidents or incidents $(n=13)$, death of a grandparent $(n=6)$, death of other family members $(n=6)$, and frightening movie $(n=3$ ) were most prevalent.

\section{Severity of Aversive Experiences in Trauma and Control Group Children}

Blind ratings of the severity of children's most frightening experience revealed that $60.5 \%$ of the experiences reported by children in the trauma group were judged as potentially traumatic. In the control group, this percentage was considerably lower (i.e., $20.9 \%$ ), $\chi^{2}(1, N=86)=13.9, p<.001$. 


\section{MURIS, MERCKELBACH, KÖRVER, MEESTERS}

Table 1. Most Aversive Experience Reported by Trauma and Control Children During the Interview

\begin{tabular}{lcc}
\hline & $\begin{array}{c}\text { Trauma } \\
\text { Group }\end{array}$ & $\begin{array}{c}\text { Control } \\
\text { Group }\end{array}$ \\
\hline Minor Accident or Incident & 7 & 13 \\
Severe Accident & 1 & 0 \\
Severe Accident of Father & 0 & 1 \\
Witness to a Severe Accident & 2 & 0 \\
Witness to a Shooting Incident & 1 & 0 \\
Witness to a Robbery & 0 & 1 \\
Death of a Parent & 3 & 1 \\
Death of a Grandparent & 5 & 6 \\
Death of Other Family Members & 0 & 6 \\
Suicide of a Parent & 1 & 0 \\
Death of a Pet & 1 & 2 \\
Severe Illness & 0 & 1 \\
Severe Illness of a Parent & 1 & 0 \\
Operation & 1 & 1 \\
Divorce/Severe Problems at Home & 5 & 2 \\
Rape & 3 & 0 \\
Physical Assault & 2 & 0 \\
Witness to Physical Assault & 0 & 1 \\
Being Threatened by a Man & 2 & 0 \\
War & 2 & 0 \\
Fire & 1 & 0 \\
Burglar & 1 & 0 \\
Getting Lost & 1 & 1 \\
Frightening Movie & 1 & 3 \\
Frightening Dream & 0 & 1 \\
Frightening Animal & 1 & \\
Damage to the House After a Minor & & 0 \\
Earthquake & 1 & \\
Being Teased & & \\
\hline a & & \\
\hline
\end{tabular}

$\mathrm{s}_{n}=43$.

\section{Traumatic Incidents, PTSD}

Symptomatology, and Anxiety

Symptoms in Both Groups

Self-report questionnaires used in this study were generally reliable in terms of internal consistency. As shown in Table 2, most Cronbach's alpha coefficients were well above .60 . For the normal group, the alphas of the PTSD-RI subscales were insufficient. This finding is hardly surprising given the small number of items on these subscales and the fact that control children scored rather low on these scales, resulting in a restriction of the variance.

Table 3 presents mean scores on PTSD-related questionnaires for both groups. An overall multivariate analysis of covariance (MANCOVA) with sex and age as covariates revealed a significant effect of group, Hotelling's $F(3,80)=39.7, p<.001$. As shown in Table 3 , children in the trauma group reported a greater number of traumatic incidents (TIS), higher levels of intrusion and avoidance (IES, PTSD-RI), and hyperarousal (PTSD-RI) than children in the control group. Thus, trauma group children indicated having experienced more traumatic incidents and displayed higher levels of
PTSD symptomatology than did children in the control group.

Within the trauma group, correlations between SCARED Traumatic Stress Disorder scores and other PTSD questionnaires were computed. Although the variance in SCARED Traumatic Stress Disorder scores was restricted because these scores were employed for selecting these children, significant and positive correlations were found between the SCARED Traumatic Stress Disorder scale, on the one hand, and TIS total score $(r=.30, p<.05)$, IES total score $(r=.34, p<.05)$, IES Intrusion $(r=.49, p<.005)$, PTSD-RI total score $(r$ $=.41, p<.01)$, PTSD-RI Reexperiencing $(r=.41, p<$ $.01)$, PTSD-RI Avoidance $(r=.33, p<.05)$, and PTSD-RI Hyperarousal $(r=.33, p<.05)$, on the other hand. Thus, higher scores on the Traumatic Stress Disorder scale were accompanied by higher scores on other self-report indices of PTSD.

Mean SCARED scores of both groups are shown in Table 4. A MANCOVA yielded a significant effect of group, Hotelling's $F(8,75)=13.8, p<.001$. Follow-up analyses of covariance (ANCOVAs) showed that, with the exception of SCARED Animal Phobia symptoms, children in the trauma group had higher levels of anxi-

Table 2. Reliability Coefficients (Cronbach's Alphas) for Questionnaires Employed in This Study

\begin{tabular}{lccc}
\hline & $\begin{array}{c}\text { Total } \\
\text { Group }\end{array}$ & $\begin{array}{c}\text { Trauma } \\
\text { Groupb }\end{array}$ & $\begin{array}{c}\text { Control } \\
\text { Groupb }\end{array}$ \\
\hline TIS Total Score & .74 & .67 & .60 \\
IES Total Score & .93 & .85 & .85 \\
IES Intrusion & .92 & .84 & .73 \\
IES Avoidance & .83 & .67 & .81 \\
PTSD-RI Total Score & .93 & .88 & .75 \\
PTSD-RI Re-experiencing & .92 & .84 & .48 \\
PTSD-RI Avoidance & .72 & .60 & .50 \\
PTSD-RI Hyperarousal & .76 & .69 & .58 \\
SCARED Total Score & .94 & .92 & .91 \\
SCARED Traumatic Stress & & & \\
$\quad$ Disorder & .81 & - & -76 \\
SCARED Panic Disorder & .81 & .78 & .76 \\
SCARED Generalized & & & \\
$\quad$ Anxiety Disorder & .81 & .79 & .80 \\
SCARED Separation & & & \\
$\quad$ Anxiety Disorder & .75 & .75 & .62 \\
SCARED Obsessive- & & & \\
$\quad$ Compulsive Disorder & .66 & .60 & .65 \\
SCARED Social Phobia & .76 & .66 & .79 \\
SCARED Blood- & & & \\
$\quad$ Injection-Injury Phobia & .72 & .75 & .71 \\
SCARED Animal Phobia & .82 & .84 & .80 \\
SCARED Situational- & & & \\
$\quad$ Environmental Phobia & .66 & .60 & .63 \\
\hline Note: & & & \\
\hline
\end{tabular}

Note: TIS = Traumatic Incidents Scale; IES = Impact of Event Scale; PTSD-RI = Posttraumatic Stress Disorder Reaction Index; SCARED $=$ Screen for Child Anxiety Related Emotional Disorders.

${ }^{a} N=86{ }^{b}{ }^{b}=43$. "The Traumatic Stress Disorder scale was used to assign children to either trauma or control group. Cronbach's alphas could not be computed for the separate groups because this scale or part of this scale had zero variance. 
Table 3. Mean Scores on Posttraumatic Stress Disorder-Related Questionnaires of Children in the Trauma Group and the Control Group

\begin{tabular}{|c|c|c|c|c|c|c|}
\hline & \multicolumn{2}{|c|}{ Trauma Group } & \multicolumn{2}{|c|}{ Control Groupa } & \multirow[b]{2}{*}{$F$} & \multirow[b]{2}{*}{$p$} \\
\hline & $M$ & $S D$ & $M$ & $S D$ & & \\
\hline TIS Total Score & 6.7 & 3.5 & 3.1 & 2.4 & 32.4 & $<.001$ \\
\hline IES Total Score & 36.3 & 7.6 & 21.2 & 5.8 & 106.6 & $<.001$ \\
\hline IES Intrusion & 17.4 & 4.2 & 9.5 & 2.4 & 118.6 & $<.001$ \\
\hline IES Avoidance & 18.9 & 4.1 & 11.7 & 4.1 & 64.4 & $<.001$ \\
\hline PTSD-RI Total Score & 35.2 & 8.5 & 20.1 & 3.7 & 115.1 & $<.001$ \\
\hline PTSD-RI Re-experiencing & 12.3 & 3.4 & 5.8 & 1.2 & 143.6 & $<.001$ \\
\hline PTSD-RI Avoidance & 7.9 & 2.5 & 4.6 & 1.2 & 63.0 & $<.001$ \\
\hline PTSD-RI Hyperarousal & 13.2 & 3.0 & 8.7 & 2.1 & 63.2 & $<.001$ \\
\hline
\end{tabular}

Note: TIS = Traumatic Incidents Scale; IES = Impact of Event Scale; PTSD-RI = Posttraumatic Stress Disorder Reaction Index. $F$ values obtained by means of univariate ANCOVAs.

$a_{n}=43$.

Table 4. Mean Scores on Anxiety Disorders Symptoms (i.e., SCARED Scales) of Both Groups

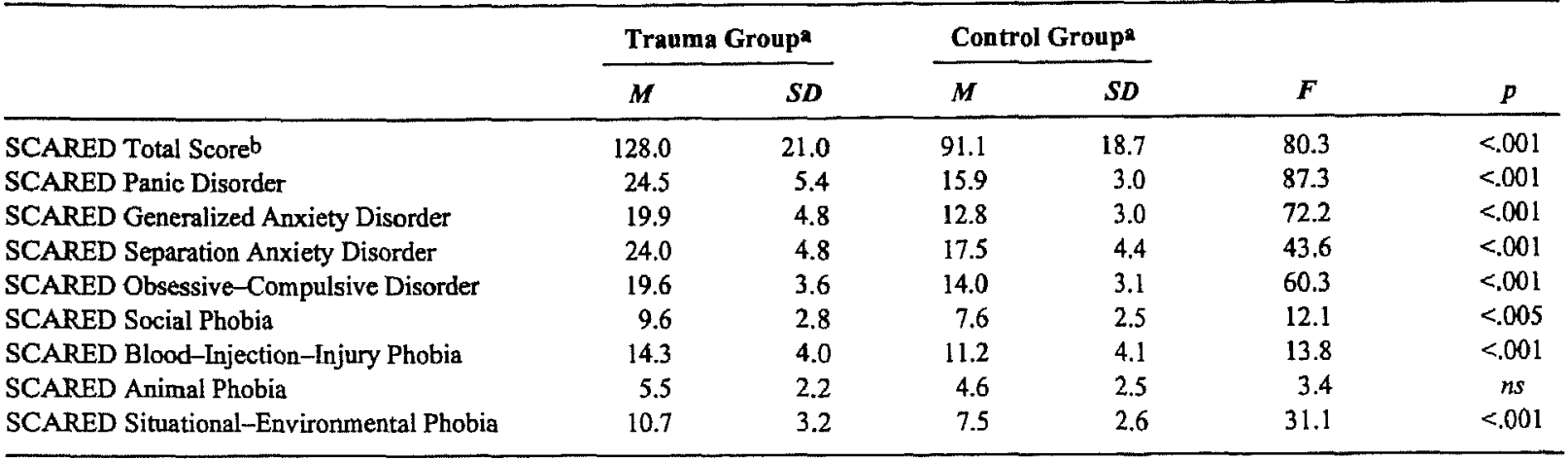

Note: SCARED = Screen for Child Anxiety Related Emotional Disorders. $F$ values obtained by means of univariate ANCOVAs.

$\mathrm{a}_{n}=43$. bScores on SCARED Traumatic Stress Disorder scale were excluded.

ety disorders symptomatology than children in the control group (see Table 4).

\section{SCARED Traumatic Stress Disorder Scale and $D S M-I V$ Criteria of PTSD}

On the basis of children's responses on the PTSD$\mathrm{RI}$ questionnaire, the percentage of children meeting the main $D S M-I V$ criteria for $\mathrm{PTSD}$ (i.e., Criterion $\mathrm{B}=$ reexperiencing; Criterion $\mathrm{C}=$ avoidance; Criterion $\mathrm{D}=$ hyperarousal) was assessed. Table 5 presents the percentages of children in both groups who fulfilled zero, one, two, or three criteria. In the control group, most children $(n=36 ; 83.7 \%)$ failed to meet any of the main PTSD criteria. In the trauma group, the majority of the children $(n=39 ; 90.7 \%)$ ful filled at least one criterion, $\chi^{2}(3, N=86)=49.6, p<.001$. Three children (all of the trauma group) met the full criteria for PTSD: These children had been exposed to a traumatic event (Criterion $\mathrm{A}$ ); they displayed all characteristic symptoms (Criteria B, C, and D); these symptoms had a duration of more than 1 month (Criterion $\mathrm{E}$ ); and it was clear that the children suffered from significant distress or impairment in normal functioning (Criterion $F$ ).
Additional analyses were carried out to determine the sensitivity (i.e., the probability that a child with PTSD symptoms was classified by the SCARED Traumatic Stress Disorder scale as having PTSD symptoms) and specificity (i.e., the probability that a child without PTSD symptoms was classified as not having the pertinent symptoms) of the Traumatic Stress Disorder scale of the SCARED. This was done by means of 2 (group: control vs. trauma) $\times 2$ (criterion: fulfilling vs. not fulfilling) cross-tabulations. Main results are shown in Table 6. Keeping in mind that the SCARED is a screening instrument, the sensitivity and specificity of the Traumatic Stress Disorder scale generally appear to be satisfactory.

\section{Discussion}

The 66-item SCARED is a recently developed selfreport instrument that intends to screen for $D S M-I V$-defined anxiety disorders symptoms in children. The main purpose of this study was to investigate the validity of the Traumatic Stress Disorder scale of the SCARED. Children with extremely high scores (i.e., trauma group) and children with extremely low scores (i.e., control group) on the Traumatic Stress Disorder scale of the 
Table 5. Frequency of Children in Both Groups Fulfilling Zero, One, Two, or Three PTSD Criteria

\begin{tabular}{|c|c|c|c|c|}
\hline & \multicolumn{2}{|c|}{$\begin{array}{l}\text { Trauma } \\
\text { Group }\end{array}$} & \multicolumn{2}{|c|}{$\begin{array}{l}\text { Control } \\
\text { Group }\end{array}$} \\
\hline & $n$ & $\%$ & $n$ & $\%$ \\
\hline No PTSD Criteria & 4 & 9.3 & 36 & 83.7 \\
\hline One PTSD Criterion & 10 & 23.3 & 4 & 9.3 \\
\hline Two PTSD Criteria & 23 & 53.5 & 3 & 7.0 \\
\hline Three PTSD Criteria & 6 & 14.0 & 0 & 0.0 \\
\hline Full Criteria for PTSD & 3 & 7.0 & 0 & 0.0 \\
\hline
\end{tabular}

Note: PTSD $=$ postraumatic stress disorder.

Table 6. Sensitivity and Specificity Percentages of the SCARED Traumatic Stress Disorder Scale in Classifying Children Fulfilling PTSD Criteria

\begin{tabular}{lcc}
\hline & Sensitivity & Specificity \\
\hline$D S M-I V$ & & \\
Criterion A: Traumatic Event & 74.3 & 66.7 \\
Criterion B: Re-experiencing & 84.8 & 90.0 \\
Criterion C: Avoidance & 90.9 & 56.0 \\
Criterion D: Hyperarousal & 92.9 & 70.7 \\
Criterion F: Distress and Impairment & 94.7 & 62.7 \\
Full criteria for PTSD & 100.0 & 51.8 \\
\hline
\end{tabular}

Note: SCARED $=$ Screen for Child Anxiety Related Emotional Disorders; PTSD = posttraumatic stress disorder, $D S M-I V=$ Diagnostic and Statistical Manual of Mental Disorders (4th ed.).

SCARED were interviewed about their most aversive life event. In addition, they completed self-report questionnaires of traumatic experiences and PTSD symptomatology. The main results can be catalogued as follows. First, children in the trauma group more often reported life events that independent judges considered to be potentially traumatic than did children in the control group. Second, on PTSD-related questionnaires, children in the trauma group reported to have experienced more traumatic incidents and displayed higher levels of PTSD symptomatology compared with children in the control group. Third, within the trauma group, SCARED Traumatic Stress Disorder scores were positively related to scores on other PTSD measures (TIS, IES, and PTSD-RI), indicating that the scale indeed possesses convergent validity. Fourth, children in the trauma group more frequently fulfilled $D S M-I V$. criteria for PTSD than children in the control group.

We must emphasize that this study relied on children who were at the extreme ends of the trauma continuum. That is, this sample consisted of children who either scored extremely low or extremely high on the Traumatic Stress Disorder scale of the SCARED. Clearly, such an approach may bias the robustness of certain effects. Thus, it remains to be seen whether similar sensitivity and specificity effects of the Traumatic Stress Disorder scale show up when a nonselected group of children is studied.
Another point worthy of note has to do with the fact that $22 \%$ of the children who scored high on the SCARED Traumatic Stress Disorder scale did not participate in this study because their parents gave no permission. Although the reason for refusal was not systematically investigated, some parents (in particular of children in the trauma group) indicated they were concerned that participation in the study would intensify their child's anxiety. Thus, it is likely that for this reason a number of severely traumatized children were missed.

Several limitations of this study deserve comment. The interview and PTSD questionnaire data were obtained 2 months after the administration of the SCARED. This delay occurred because the data of almost 1,000 children had to be collected and processed. Thus, one could question the validity of our attempt to relate children's SCARED responses to data that were collected 2 months later. This issue becomes even more relevant when one acknowledges the fact that the testretest stability of the SCARED Traumatic Stress Disorder scale appears to be rather modest (Muris, Merckelbach, Van Brakel, \& Mayer, 1999). In fact, both factors (time delay and modest test-retest reliability) worked against the detection of a robust connection between SCARED Traumatic Stress Disorder scale and the interview and subsequently obtained questionnaire data. Even so, a vast majority of children indicated that their responses to the Traumatic Stress Disorder items of the SCARED did, indeed, pertain to their most aversive experience as identified during the interview. As well, the Traumatic Stress Disorder scale of the SCARED proved to possess predictive validity in that children with high scores on this scale reported more severe events and displayed higher levels of PTSD symptomatology than did children with low scores. Another limitation pertains to the fact that the research assistant who carried out the interviews was not blind to children's group status. However, the interview was highly structured, and material was evaluated by independent, blind raters (e.g., trauma vignettes, PTSD criteria). A third shortcoming of this study concerns the fact the DSM-IV criteria for PTSD symptoms were assessed by means of children's responses during the interview and their scores on the PTSD-RI. It would have been preferable if we had relied on a standardized diagnostic interview instrument to establish these criteria.

An additional finding of this study is that children in the trauma group exhibited elevated levels of not only PTSD symptoms but also anxiety disorders symptoms. Although such a connection between aversive life events and anxiety disorder symptomatology is in line with the results of previous studies (Benjamin et al., 1990; Goodyer et al., 1990; Kashani et al., 1990), the causal direction of this connection is open to several interpretations. One possibility is that aversive life experiences predispose to a broad spectrum of anxiety 
disorders. This interpretation accords well with the observation that pure PTSD is the exception rather than the rule and that in most individuals with PTSD, secondary psychiatric symptoms appear to develop over time (for a review, see Yehuda \& McFarlane, 1995). Alternatively, perhaps certain types of aversive events (e.g., assaults) have a heightened frequency in anxious children because they are less successful in avoiding such events. Still another possibility is that aversive incidents have a greater impact in children who already display high levels of anxiety. Future longitudinal studies in which premorbid levels of anxiety are assessed and in which the occurrence of aversive events is prospectively recorded could elucidate this causality issue on the relation between trauma and comorbid anxiety symptoms.

Over the past few years, a series of studies have investigated the psychometric qualities of the SCARED (for a brief review, see Muris et al., 1998). These studies have demonstrated that the SCARED is a valid and reliable measure to screen for $D S M-I Y$-defined anxiety disorders symptoms in children. This study adds to this conclusion by showing that the SCARED Traumatic Stress Disorder scale can be useful as an initial screen for detecting children who have been confronted with traumatic life events and who are at risk for developing PTSD.

\section{References}

American Psychiatric Association. (1994), Diognostic and statistical manual of mental disorders (4th ed.). Washington, DC: American Psychiatric Association.

Benjamin, R. S., Costello, E. J., \& Warren, M. (1990). Anxiety disorders in a pediatric sample. Journal of Anxiety Disorders, 4, 293316.

Bernstein, D. P., Ahluvalia, T., Pogge, D., \& Handelsman, L. (1997). Validity of the Childhood Trauma Questionnaire in an adolescent psychiatric population. Joumal of the American Academy of Child and Adolescent Psychiatry, 36, 340-348.

Birmaher, B., Khetarpal, S., Brent, D., Cully, M., Balach, L., Kaufman, J., \& McKenzie Neer, S. (1997). The Screen for Child Anxiety Related Emotional Disorders (SCARED): Scale construction and psychometric characteristics, Joumal of the American Academy of Child and Adolescent Psychiatry. 36, 545-553.

Clarke, G., Sack, W. H., \& Goff, B. (1993). Three forms of stress in Cambodian adolescent refugees. Joumal of Abnomal Child Psychology, 21, 65-77.

Curry, J. F., \& Bennett Murphy, L. (1995). Comorbidity of anxiety disorders. In J.S. March (Ed.), Anxiety disorders in children and adolescents (pp. 301-317). New York: Guilford.

Dyregrov, A., Kuterovac, G, \& Barath, A. (1996). Factor analysis of the Impact of Event Scale with children in war. Scandinavian Joumal of Psychology. 37, 339-350.

Famularo, R., Kinscherff, R, Fenton, T. (1990). Symptom differences in acute and chronic presentation of childhood post-traumatic stress disorder. Child Abuse and Neglect, 14, 439-444.

Fon, E. B., Riggs, D.S., \& Gershuny, B. S. (1995). Arousal, numbing and intrusion: Symptom structure of PTSD following assault. American Joumal of Psychiatry, 152, 116-120.

Goodyer, 1., Wright, C., \& Altham, P. (1990). The friendships and recent life events of anxious and depressed school-age children. British Journal of Psychiatry. 156, 689-698.
Horowitz, M. J., Wilner, N., \& Alvarez, W. (1979). Impact of Event Scale: A measure of subjective stress. Psychosomatic Medicine. 4l. 209-218.

Kashani, J. H., Vaidya, A. F., Soltys, S. M., Dandoy, A. C., Katz, L. M., \& Reid, J. C. (1990). Correlates of anxiety in psychiatrically hospitalized children and their parents. American Joumal of Psychiatry, 147, 319-323.

Lonigan, C. J., Shannon, M. P., Finch, A. J., Daugherty, T. K., \& Saylor, C. M. (1991). Children's reactions to a natural disaster. Symptom severity and degree of exposure. Advances in Behaviour Research and Therapy, 13, 135-154.

March, J. S., Amaya-Jackson, L., Terry, R., \& Costanzo, P. (1997). Posttraumatic symptomatology in children and adolescents after an industrial fire. Soumal of the American Academy of Child and Adolescent Psychiatry, 36, 1080-1088.

Muris, P., Merckelbach, H., Mayer, B., \& Prins, E. (2000). How serious are common childhood fears? Behaviour Research and Therapy, 38. 217-228.

Muris, P., Merckelbach, H., Mayer, B., Van Brakel, A., Thissen, S., Moulaert, V. \& Gadet, B. (1998). The Screen for Child Anxiety Related Emotional Disorders and its relationship to traditional anxiety measures Joumal of Behavior Therapy and Experimental Psychiatry, 29, 327-339.

Muris, P., Merckelbach. H., Schmidt, H., \& Mayer, B. (1999). The revised version of the Screen for Child Anxiety Related Emo. tional Disonders (SCARED-R): Factor structure in normal children. Persomality and Individual Differences, 26, 99-112.

Muris, P., Merckeibach, H, Van Brakel, A., \& Mayer, B. (1999). The revised version of the Screen for Child Anxiety Related Emotional Disorders (SCARED-R): Further evidence for its reliability and validity. Anxiety, Stress, and Coping, 12, 411-425.

Nader, K., Stuber, M., \& Pynoos, R. (1991). Posttrumatic stress reactions in preschool children with catastrophic illness: Assess ment needs. Comprehensive Mental Health Care, 1, 223-239.

Ollendick, T. H. (1983). Reliability and validity of the Revised Fear Survey Schedule for Children (FSSC-R). Behaviour Research and Therapy, 23, 465-467.

Pynoos, R. S., Frederick, C., Nader, K., Arroyo, W., Steinberg, A., Eth, S., Nunez, F., \& Fairbanks, L. (1987). Life threat and posttraumatic stress in school-age children. Archives of General Psychiarn, 44, 1057-1063.

Pyooos, R. S., \& Nader, K. (1988). Psychological first aid and treatment approach for children exposed to community violence: $R e-$ search implications. Joumal of Trowmation Stress, 1, 243-267.

Reynolds, C. R., \& Richmond, B. O. (1978). What I think and feel: A revised measure of children's manifest anxiety. Journal of $A b$ normal Child Psychology, 6, 271-280.

Shannon, M. P., Lonigan, C. J., Finch, A. J., \& Taylor, C. M. (1994). Children exposed to disaster: I. Epidemiology of post-traumatic symptoms and symptom profiles. Joumal of the American Acadeny of Child and Adolescent Psychiaty. 33. 80-93.

Terr, L. (1979). Children of Chowchilla: A study of psychic trauma. Psychoanalytic Study of the Child, 34, 547-623.

Wolfe, V. V., Gentile, C., \& Wolfe, D. A. (1989). The impact of sexual abuse on children: A PTSD formulation. Behavior Therapy, 20(2), 215-228.

Yehuda, R., \& McFarlane, A. C. (1995). Conflict between current knowledge about postraumatic stress disorder and its original conceptual basis. American Joumal of Psychiatry, 152, 1705-1713.

Yule, W., \& Udwin, O. (1991). Screening child survivors for posttraumatic stress disorders: Experiences from the "Jupiter" sinking. Britush Journal of Clinical Psychology, 30, 131-138.

Yule, W., \& Williams, R. M. (1990). Post-traumatic stress reactions in children. Joumal of Traumatic Stress, 3, 279-295.

Manuscript received May 6, 1999

Final revision received November 22, 1999 